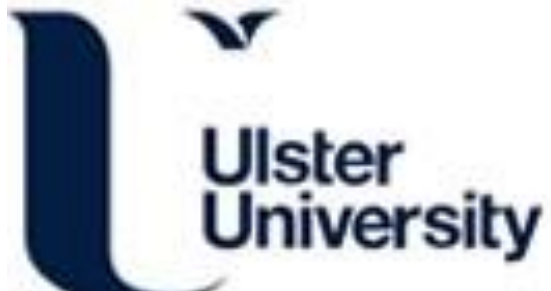

Inside the RUC: Information Technology and Policing in Northern Ireland

Hoey, A. (1998). Inside the RUC: Information Technology and Policing in Northern Ireland. International Review of Law, Computers \& Technology, 12 (1), 15-26.

Link to publication record in Ulster University Research Portal

\section{Published in:}

International Review of Law, Computers \& Technology

Publication Status:

Published (in print/issue): 01/01/1998

\section{Document Version}

Publisher's PDF, also known as Version of record

\section{General rights}

Copyright for the publications made accessible via Ulster University's Research Portal is retained by the author(s) and / or other copyright owners and it is a condition of accessing these publications that users recognise and abide by the legal requirements associated with these rights.

\section{Take down policy}

The Research Portal is Ulster University's institutional repository that provides access to Ulster's research outputs. Every effort has been made to ensure that content in the Research Portal does not infringe any person's rights, or applicable UK laws. If you discover content in the Research Portal that you believe breaches copyright or violates any law, please contact pure-support@ulster.ac.uk. 


\section{Inside the RUC: Information Technology and Policing in Northern Ireland}

\section{Amanda Hoey}

To cite this article: Amanda Hoey (1998) Inside the RUC: Information Technology and Policing in Northern Ireland, International Review of Law, Computers \& Technology, 12:1, 15-26, DOI: $10.1080 / 13600869855540$

To link to this article: http://dx.doi.org/10.1080/13600869855540

曲 Published online: 21 Jul 2010.

Submit your article to this journal $\widetilde{ }$

ఋ Article views: 37

Q View related articles $\circlearrowright$

4 Citing articles: 3 View citing articles ๘ 


\title{
Inside the RUC: Information Technology and Policing in Northern Ireland
}

\author{
AMANDA HOEY
}

\section{Introduction}

Enhanced effectiveness and efficiency are generally accepted as the rationale for introducing technical change within any organization, the police being no exception. Since the early 1970s the concept of 'computerized policing' has been evolving in line with technological advances and the changing nature of policing. Information Technology is used in this context to describe the 'computerization' of tasks which otherwise would have been conducted manually within the police service.

Information Technology has been used within the police service to gather and manage all sorts of information (information management) and to facilitate the efficient deployment of manpower and enable quick responses (command and control). No measurement or evaluation of the technology's benefit was ever published, but the police service generally applaud the early systems and regard them as a success. The 1990 s has heralded a new era in computerized policing, but it has been claimed that 'much of the recent innovation by the police seems to be motivated simply by the faith that the new technology must be helpful because it has been widely adopted by many other types or organization'. ${ }^{1}$ This undoubtedly is true as IT has become pervasive throughout society but at the same time there has been a growing realization within the police service itself that computerization can lead to enhanced efficiency, competency and professionalism. IT is becoming recognized as a valuable tool which is the way forward for policing in general,

The police have traditionally been encouraged to invest in people rather than technology. Because of this we have reached a point of imbalance where we realize we need to invest more in IT to empower the ordinary constable doing his or her job. ${ }^{2}$

In the early 1990s a series of studies into the development of an information systems strategy for the whole police service in England and Wales were undertaken. This followed proposals which recommended that 'a central police information strategy should be developed for the police service. This should be more prescriptive than general guidelines'. ${ }^{3}$ The result was the formulation of a National Strategy for Police Information Systems (NSPIS) which was launched at the end of 1994.

Correspondence: Amanda Hoey, Lecturer in Law, School of Public Policy, Economics and Law, University of Ulster at Jordanstown, Newtownabbey Co. Antrim, Northern Ireland BT37 OQB; e-mail $<$ A.Hoey@ulst.ac.uk>. 
The basis of the NSPIS rests on the premise that all police forces carry out same processes and therefore it should be possible to define a common set of information systems to support those processes rather than having forces individually defining their own and adopting an ad hoc approach to implementing IT. As Ackroyd et al. point out there has been a considerable difference in the extent and sophistication of technology employed throughout the police forces in the UK. In their study into the use of IT and the police it was discovered that West Yorkshire, Lancashire and Merseyside, for example, were moving towards the integration of all their systems. At the same time other forces had few systems at all. This was attributed to the varying size and financial resources of the constabularies, as well as differing management philosophies and the fact that each constabularly jealously guards its own independence. ${ }^{4}$ The NSPIS was generally welcomed by police forces in the hope that it 'would reduce wasteful duplication of effort within individual forces and enable the more efficient use of information'.

How then have forces within the UK been implementing IT and to what extent is technology seen as a strategic issue? This article explores these issues with reference to the Royal Ulster Constabulary. There is no such thing as a 'representative' force but the RUC was chosen as a case study because, among the UK forces, it is presently one of the leaders in the design and adoption of information technology. Other forces are also taking the lead and developing their own integrated systems, largely due to delays in the roll-out of software under the NSPIS and concerns about how the national strategy concept of interoperability will work in practice. Essex police force, for example, has developed its own integrated system called 'Epics' which is claimed to be 'four years ahead of the national strategy'. ${ }^{6}$ Other forces including Dorset, Northumbria and Kent are also developing their own integrated systems. At the same time specific police forces are developing eight key NSPIS applications, and it is reported that at least 27 of the 43 UK forces have indicated a commitment to take this software by $1999 .^{7}$ Thus it is evident that IT has become a vital and integral part of policing, with forces pushing ahead rapidly with the implementation of systems designed to meet the needs of their organisation.

\section{The Royal Ulster Constabulary}

This article focuses on the development and use of IT systems within the Royal Ulster Constabulary (RUC) in Northern Ireland. ${ }^{8}$ Within Northern Ireland there are two bodies responsible in different ways for the policing of the province, the RUC being one and the Police Authority for Northern Ireland (PANI) the other. ${ }^{9}$ The RUC was formed in 1922 to replace the Royal Irish Constabularly which had policed the whole of Ireland until partition. Prior to 1970 the RUC was accountable to the Minister of Home Affairs in the Northern Ireland government. Civil disturbances in 1968-69 caused the UK government to set up an Advisory Committee to examine the organization and structure of the RUC and it was recommended that an independent body should be set up to monitor the RUC's activities. Hence the Police Authority for Northern Ireland was established which continues to work closely with the RUC. As in other legal systems the primary role of the RUC is to prevent and detect crime. However, unlike many other legal systems the RUC have been faced with the constant threat of injury and death by terrorist activities since the outbreak of civil disturbances in 1968. The ceasefires of Autumn 1994 have changed the situation. This 'has had a profound effect on policing' in Northern Ireland and in the context of information technology it has allowed expenditure of up to $£ 4 \mathrm{~m}$ a year to be planned to at least the turn of the century. ${ }^{10}$ 
The RUC is responsible for policing 5242 square miles with a population of approximately 1,500,000. The force itself is set at 8489 regular officers, 3202 full-time reserves and 1765 part-time reserves. ${ }^{11}$ Approximately 2550 civilians provide administrative, professional and technical support. The force is organized on an operational basis into:

- 7 headquarters departments

- 3 geographic regions

- 2 divisions (4 in Greater Belfast)

- 39 sub-divisions (19 in Greater Belfast)

- 97 police stations manned 24 hours a day and 51 limited-opening stations.

The hierarchy of responsibility within the RUC is as follows: stations are responsible to each sub-division (approx. 3-4); sub-divisions (3) report to each division; each division is responsible to the Assistant Chief Constable for their region. Each Assistant Chief Constable reports to a Deputy Chief Constable, of which there are two, one for support services and the other for operations, and ultimately to the Chief Constable at RUC Headquarters.

The Police Authority for Northern Ireland works closely with the RUC on all aspects of policing. In the context of computerization the Police Authority Technology Group (PATG) is a branch within Support Services of the Police Authority for Northern Ireland. It comprises approximately 200 civil servants both technical and administration. The group was established in 1993 when the then Police Authority Telecommunications Branch and Computer Branch amalgamated. The PATG works in conjunction with the Computer Services Branch of the RUC regarding the design and implementation of IT within the police force. Computer Services Branch is responsible for determining the ways in which IT can assist the force in meeting its strategic objectives and for identifying training needs for computer systems within the force.

\section{Computerized Policing in the RUC}

The history of computerization within the RUC, and indeed many of the forces in the UK, has been chequered. Throughout the 1980 s the approach to implementing IT in the RUC was piecemeal, but the early 1990s have witnessed a radical overhaul of the police service's approach to the incorporation of IT within the organization.

Many developments have taken place initiated by the RUC itself and by the UK government. Various examples of how sophisticated technology can be connected to the functions of policing are provided in this article as it explores how technology can support the routine core functions of policing.

The activities carried out within a police force can be identified as follows:

- Service delivery-provision of services such as responding to incidents, operations, intelligence;

- Strategy-development of plans, policies etc.;

- Support services-criminal justice administration, personnel, finance.

Within these three major areas there are various processes which are carried out, and the key issue to be explored in this article is how can IT give support to these processes. The main aim of a police force in general is to prevent and combat crime and to provide an efficient and effective service to the community. How then do the police go about their routine tasks with the aid of technology? 
Within the context of delivering a service to the community technology can be used in a variety of ways. The police need information in order to do their job. Police detect very little crime themselves but rely heavily on information from the public about the commission of crimes. Also in order to plan operations, carry out surveillance or identify likely suspects in a criminal investigation they will need information such as geographic details, physical descriptors and the like. Technology can be used in order to enhance the operational effectiveness of the police by allowing vast amounts of information to be stored in readily accessible form, enabling the police to deploy resources efficiently and finally by aiding the police in large-scale preservation of law and order. The core function of policing is to prevent and combat crime, and this article explores some of the uses of technology in this area. The key activities in which the police will be involved comprise investigation, patrolling, intelligence, gathering information, crime analysis and surveillance.

In developing strategies, whether it be for a small-scale operation or the management of the police force nationally, technology again comes into play. Computer applications relating to crime analysis, command and control, surveillance and administration may be useful in this context. It is clear that some of the techniques described in this article may be of use in a variety of contexts, and there will be an overlap between the functionality of the technology in service delivery and strategy development. The third area of activity is the provision of support services. In this field technology is used for efficient management and administration purposes.

Between July and November 1991 a study was commissioned by the joint RUC/PANI Information Systems Steering Committee who have responsibility for overseeing the implementation of information systems along with Computer Services Branch of the RUC who are ultimately responsible for the implementation of such systems. Previously in 1987 an IT Enabling Study had been carried which identified a need to increase staff resources and formulate an Information Systems (IS) strategy. In light of staff increases and the perceived lack of progress since the 1987 study a scoping study was conducted by Mr. Paul Griew, with the object of reviewing the current provision of information systems in the RUC. $^{12}$

\section{Formulating an Inform ation System s Strategy}

The Study's terms of reference were to identify the key factors that will impact on the development of an IS strategy, to identify areas where work needs to be done, to recommend how an IS strategy should proceed and finally to produce a draft report. The Study involved interviewing senior RUC personnel, staff from other government departments such as the Northern Ireland Office and the Department of Finance and Personnel in the Northern Ireland Civil Service.

The study found that information systems were seen as a priority area, but there was a clear lack of senior management commitment in this area. The potential of IT was not thoroughly understood and the lack of an IS strategy necessarily meant a lack of an IT strategy. The study identified problems with lack of resources, cumbersome procedural hurdles for approval of projects, and a lack of cohesion between PANI and the RUC. In light of these findings the study identified an urgent need for some direction and development of an IS strategy. The purpose of the strategy is to 'facilitate an orderly and agreed development of Information Systems within an organization'. For this to be effective you must have appropriate planning mechanisms, management structures and resources to implement the agreed systems. 
The Enabling Report had already established that the information systems could be clearly split into two groups: operational and administrative. The Griew Report felt that it would be better for these systems to operate on a common infrastructure in order to reduce overall cost and also increase the availability of information. The idea was to have a common infrastructure consisting of not just one platform but series of common platforms of hardware, development software and networks based on the following principles:

- all systems must be accessible from all terminals

- all systems should have same 'look and feel'

- single pieces of data need only be entered once

- single pieces of data need only be stored once

- location and structure of any piece of data should be known before it is required,

- all systems should use the same technical infrastructure, including network.

As a result of the Griew Report the RUC/PANI commenced a strategy study whose primary aim was 'to develop an information systems strategy which lays plans and sets standards a co-ordinated and integrated approach to the provision and management of systems over the next five years or more'. The starting point was to ensure that the strategy would support and further the three main aims of the corporate Authority's strategy which is based on the Chief Constable's six strategic goals for 1991.

\section{IT and the Objectives of the RUC}

Before identifying IT systems for use we need to identify the context in which these systems are to operate. The RUC's objectives are outlined below:

- to reduce the incidence of terrorism

- to enhance the relationship between the police force and all sections of the community

- to reduce the incidence and enhance the detection of non-terrorist crime

- to reduce the incidence of road traffic accidents

- to maintain public order

- to progress the support priorities of the force in order to enhance its organizational effectiveness.

IT can play an integrative part in many of these objectives, operational systems being a priority and management information systems being useful. The main functions of the RUC include top-level management, public relations, complaints and discipline, uniformed policing, management of civilian/police personnel, support to uniformed policing such as operational policy and planning, traffic planning and community relations. Other functions include the identification of infrastructure requirements (including communications and information systems), CID investigations including support services and Special Branch. ${ }^{13}$

Clearly the RUC requires support services adequate to ensure the fulfilment of its goals. These support services are also required for raising standards, improving quality and focusing on effectiveness. How can IT facilitate these objectives? It was evident that the existing diversity of systems exposed a need for an integrated approach both on the mainland and in Northern Ireland. ${ }^{14}$ A leading external consultant compiled an extensive 
study of the business needs of the RUC/PANI. The areas which needed to be addressed were identified as follows:

\section{- Office Automation}

- Manpower Planning

- Administration

- Command \& Control $^{15}$ Message Handling (C\&C/MHS)

The final report of the RUC/PANI was issued in Febuary 1993 and contained the conclusions of the strategy study conducted over the period 1992-93 and proposals for addressing the issues within the strategy. The benefits of defining an IS strategy were to:

- support the functions and objectives of RUC/PANI;

- to remedy weaknesses in the existing systems;

- to save money and increase operational effectiveness.

On the basis of this final report innovative change was about to transform the way in which technology is used within the police force in Northern Ireland. A continuous programme of change was implemented in line with the eight-year plan set out in the IS strategy. The future systems for the RUC are based on developments already underway in the short term and to go forward they include:

- the introduction of office automation on a much wider scale

- the early availability of current developments, including Criminal Intelligence System (CIS), Manpower Administration and Registry System (MARS), Fleet support and the Stores, Purchasing and Finance system

- the replacement of the old Computer Assisted Policing (CAP) Message Handling System (MSX) and the Criminal Information and Retrieval System (CIRS)

- Automatic Fingerprint Recognition (AFR)

Police forces have to be responsive and the development of an IS strategy allows for direction and prioritization. The main aims of the RUC/PANI strategy are to provide for a co-ordinated and integrated approach to the provision and management of information systems for the next five years or more, and thus assist in achieving the RUC/PANI objectives, to address immediate problems regarding existing systems and ultimately to establish a framework and environment which will enable the strategy to be implemented.

A recent IS Strategy Review was published in August 1996. This recognized that much had been achieved since December 1992, and the purpose of the document was to review the implementation progress and comment on the continuing validity of the strategy. The 1992 strategy had concentrated on providing essential new and replacement systems in line with the key areas identified in the Griew Report.

Below is a summary of the systems already delivered and those which are in the procurement and implementation process:

\section{System s Delivered}

Automatic fingerprint recognition (AFR) this system was installed in January 1994 and is supplemented by DABS providing administrative support. It relates fingerprints stored in AFR to details of individuals. On the whole the review concluded that AFR and the overall project have been very successful. AFR has greatly enhanced the ability to speed up the detection of suspects. Before this had to be done on the basis of manual comparisons which 
was extremely time-consuming. Now fingerprints are scanned into the computer and a search is conducted for similar prints held within the database. This is a central system set up solely within Northern Ireland. ${ }^{16}$

Finance and stores; the Finance system became operational in April 1994 followed by Stores and Purchasing functions in April 1995. The applications are in use in PATG and RUC stores and are considered to be operating successfully.

Fleet management; TRANMAN package became operational in mid 1995. It is a well proven system, but much time has been spent on integrating various modules. It is used jointly by RUC and PATG transport organizations.

Firearms licensing; this is a comprehensive and successful application developed in-house which became operational early in 1996.

Intelligence systems; a general purpose system pilot project was commenced in April 1994 which supports about 30 users at headquarters and three Criminal Intelligence Offices. There are plans afoot to build a force-wide system based on the successful pilot.

\section{System s in Procurement and Implementation}

ATLAS; this system will provide a new communications infrastructure at a cost of approximately $£ 9 \mathrm{~m}$. It is intended to replace the ageing C\&C and message-handling systems. It was implemented in Greater Belfast in December 1996 and the aim is to complete the implementation process by December 1997 for the rest of Northern Ireland. $M A R S$; this system consists of an office-automation infrastructure at each sub-division. The cost has been estimated at about $£ 1.2 \mathrm{~m}$ for the 39 sub-divisions. Currently 12 MARS installations are operational and there is a roll-out plan to early 1998. The main criticism of the system is that the word-processing facilities require migration to a more commonly used and user-friendly application.

PACIFIC; this is the name given to a force-wide replication of the pilot CIS system. The estimated cost is at approximately $£ 700 \mathrm{k}$ in $96 / 97$. The system will support about 200 users at 70 locations and will utilize the ATLAS communications infrastructure. Implementation is planned to commence March 1997.

ICIS; this is the Integrated Criminal Information System which will combine some or all of the following:

- criminal records

- crime reporting

- custody control

- criminal intelligence

The project is currently at its feasibility stage to determine its scope and to consider how to make better use of criminal information across all the police activities that generate and use it. At a minimum the new ICIS system will replace the existing CIRS which is equivalent to the PNC in GB. It is hoped to integrate the ICIS system with PACIFIC. Prototyping is being used to test the concepts underpinning the system.

Complaints and discipline This system is at the early stages of analysis. It is intended that it will support the management of processes involved in complaints against officers.

Strategic Planning and MIS (Management Information System); analysis of such a system is currently being carried out. It was recognized in the 1996 Review that there is an obvious 
need for good management within the RUC as an organization. Phase 1 of MIS implementation started in May 1997.

Before ascertaining the extent to which the implementation of an IS strategy has benefited the RUC, two of the aforementioned systems deserve more detailed attention. It was on the basis of the strategy study report published in December 1992 that the largest ever public sector IT project in Northern Ireland commenced under the auspices of the PATG. The main components of the project were the ATLAS and MARS systems.

\section{Atlas}

This project was set up to replace the original Message Switching to provide a faster and more efficient province-wide message-handling system. The new messaging system is an international standards based system and retains the community messaging facility of the original MSX system but which will also allow Interpersonal Messaging (IPMS) functionality for selected users with PCs connected to the Data Network. The ATLAS Project comprises provisioning for a provincewide network infrastructure together with provincewide Command and Control (C\&C) and Message Handling Systems (MHS). The network is designed immediately to support C\&C/MHS and MARS, and progressively approximately another 18 IT systems in total. It is a secure network within which the various systems can interact. The systems are standards-based to allow inter-system connectivity thus enhancing interoperability between various departments/branches of the RUC/ PANI. This use of open systems technology allows multi-vendor procurement. The ATLAS C\&C/MHS system applications are Windows-based and provide forcewide services all day, every day. The first phase of ATLAS implementation comprising provincewide provision of network and MHS services and C\&C in Greater Belfast was completed in December 1996 with the Phase 2 roll-out of C\&C to rural sub-divisions to be completed by November 1997. The operational benefits of the ATLAS system can generally be summarized as follows:

- it permits increased functionality since messages up to a rolling 13 months old can be recovered; and

- it facilitates a reduction in paper work.

The functionality of ATLAS comprises the following:

- incident logging-every 999 call made to the police is logged in the central control room based at Castlereagh in Belfast. This has been the case since 1978 when CAP (Computer Assisted Policing) was introduced into Belfast

- incident management-information concerning an incident reported to the police or regarding which action was taken will be kept on line for 13 months. This will be of immense importance in connection with legal issues such as rules of disclosure and for solicitors who may need the information contained within the system for legal purposes.

- resource allocation - at the beginning of every shift the number of officers available and their respective duties are keyed into the system. 'Officers on duty' information is also logged into MARS, C\&C and the vehicles application.

- mapping information, management information, contingency planning and keyholder information are other aspects of ATLAS's functionality.

This information can be accessed from common terminals placed under the control of Sub-Divisional Commanders who are in charge of areas commonly referred to as 'patches'. Due to the development of resources and facilities the information contained on the ATLAS system is available at the touch of a button across the province. 


\section{Mars}

MARS is the acronym for the RUC's Manpower, Administration and Registry System. These were viewed as being the key areas of IT support in sub-divisions. Since 1988, consultation had been taking place with Sub-Divisional Commanders in order to ascertain Sub-Divisional needs for Administrative Support. The aim of the MARS project is to provide a high-quality office automation and word-processing facilities to the police force across NI. A three-year implementation programme began in 1995, and it is hoped that this will be complete by early 1998 .

The manpower aspect of the system provides for operational planning by providing a clear and concise duty sheet and an overview of manpower within each sub-division. The system was designed in-house by the Police Authority Technology Group using Informix, a fourth-generation programming language, and Uniplex, a sophisticated and widely used Office Automation and Business Support software.

At present duty sheets are prepared manually, and thus MARS will eliminate this time-consuming task by creating and updating duty sheets which are incorporated automatically into the system. Also, amendments will no longer take place manually but instead the relevant data is input as well as overtime. On the basis of these changes the computer retains this information and can thus assist in planning and monitoring overtime. This information can then be extracted at any station. Greater efficiency is obviously one aim of the system and since only authorized personnel can amend duty sheets security is also a priority.

Sub-divisional Registries are currently kept containing manual files regarding incidents. This involves entries on index slips which may be multiple, such as parties involved, location of accident, solicitor, investigating officer, etc. Preliminary reports have to be filled out and binders kept. MARS will allow for a single entry regarding a particular incident which can then be easily accessed at the touch of a button, compared to the present situation-for example in Head Quarter's crime branch up to 500 green binders are 'live' at any one time.

A lack of word processing support was identified in the 1992 strategy study, and MARS is designed to remedy this by providing word processing, standardized forms and a standard word-processing product to facilitate training of end users and staff mobility. Whereas MHS is designed to facilitate receipt or delivery of important messages, MARS will be used to transfer inter-personal documents which have been prepared by typists prior to questioning or answering by the Sub-Divisional Commander which then are output and maintained on the archives of the main host computer. One point raised in the 1996 Review was that at present there remains a mixed Uniplex/Windows office automation environment within the RUC/PANI. The Review pointed out that globally Windows is the de facto standard. A mixed environment does not make sense, and a common situation is that police officer and civilian support staff working together cannot communicate through each other's system. There is a clear need to adopt a single environment to improve effectiveness and efficiency, but there are other strategic reasons for moving to Windows. Windows provides a family of products for networked computing which includes a safe and reliable operating system. It provides flexibility in building systems and integrating them and its almost universal usage has led to a wide range of low-cost products and expertise in using them. Using Windows would be in-line with industry trends and the types of software products being developed today, and therefore it would be more practical to move to a standardized Windows environment. 


\section{Future IS Strategy}

The business environment in which police forces operate is changing ${ }^{17}$ and the development of an IS strategy allows a formalized approach to planning for information systems. The 1996 Review recommended that the current RUC strategy should not be fundamentally altered but should be amended to take into account changing environment and the nature of future IS requirements and the available technology. Information technology is viewed as a 'key element in supporting the business objectives of the Police Service'. ${ }^{18}$ The table below illustrates how the present systems support or are planned [ ] to support the business objectives of the RUC.

\section{Objective}

System

To reduce incidence of terrorism

To enhance the relationship between the

PRISM, CIS, [PACIFIC]

police and all sections of the community INTERNET,

by increasing public confidence and support

[Complaints and Discipline]

To reduce the incidence of and enhance the

AFR, Firearms, CIRS, [ICIS] detection of non-terrorist crime

To maintain public order

[ATLAS]

To recruit, train, retain and motivate the [RUC Personnel], [Training Support] officers needed to achieve the RUC's objectives

To refine the organizational effectiveness of the RUC

MARS, Fleet Management

Thus far we can see that the RUC has been at the fore in producing innovative and productive IT applications in order to provide a more effective and efficient police force for Northern Ireland.

\section{Conclusion}

The use of technology within policing in general is obviously not without controversy, but it appears that police use of technology is expanding. The RUC now have use of technology which permits surveillance, identification, detection, enhanced information processing, communication, etc. Information technology is increasingly being viewed as one of the cornerstones of an efficient police service and police crime-prevention strategy. The benefits of computerization for policing are commonly accepted as providing increased efficiency, both in administrative and operational terms, faster incident access, enhanced speed of despatch and the provision of archive information.

In a recent article in Computing the retiring Scottish Chief Inspector of Constabulary, John Boyd, is reported as having claimed that crime-fighting applications have helped improve crime-detection rates in Scotland during the last few years. ${ }^{19}$ In his Annual Report to Chief Constables he stated that IT systems were essential for effective policing. Figures published by the Scottish Office showed an increase in detection rates from 31\% in 1991 to $39 \%$ in $1995 / 96 .^{20}$

In the particular context of the RUC in Northern Ireland the 1996 Information Systems Strategy Review illustrates that there has been a growing awareness and enthusiasm for IT. The impact of the IS strategy has led to a better approach than the previous ad hoc 
approach; police requirements appear to be better taken into account, and there is evidently a good understanding of IS/IT capabilities within the force. Despite the fact that there have been no formal measures of the level of the benefits attained it appears to be generally accepted that the benefits of implementing an IS strategy are identified as follows:

- it has facilitated a reduction in administrative and unproductive work;

- it has improved the quality of police work in that there is better accuracy and quality of crime investigation;

- it has enabled some reduction in typing-pool sizes;

- it has facilitated some civilianization.

Despite that fact that computerization has been applauded it has not been without its difficulties. Chief Inspector of Constabulary, Sir Trefor Morris, in his 1996 Annual Report slammed many of the UK forces for not having a comprehensive IT strategy despite the 1994 NSPIS. The RUC was not technically within scope of the national strategy, but it may be useful to identify how well NSPIS implementation is likely to match RUC needs and priorities. The main difference between Northern Ireland and England and Wales is the relative priority given to different types of crime. In Northern Ireland combatting terrorism has the highest priority, whereas in England and Wales there is a concentration on violent crime such as burglary and crimes of particular local concern.

In many areas the RUC has or is acquiring systems either at or above the level of sophistication expected from NPSIS, e.g. ATLAS, AFR, PACIFIC. Local developments such as ICIS would not be feasible on a national basis due to the size and complexity of such an application, but it could be useful for individual forces. Some of the current NSPIS applications which might support RUC needs include:

\section{- Complaints}

- Personnel management

- Training administration

- Custody and related areas (case preparation etc.)-low priority for RUC

The RUC intend to monitor national developments in line with their own current plans and to take decisions on a case-by-case basis.

It appears that information technology is increasingly recognized as being a valuable and innovative addition to policing within Northern Ireland. The durability and functionality of the systems discussed in this article will continually need to be reassessed in light of technological refreshment and the changing nature of policing.

Amanda Hoey

University of Ulster at Jordanstown

Northern Ireland

\section{Notes and References}

The author gratefully acknowledges the assistance provided by Computer Services Branch of the RUC.

1 Ackroyd et al. New Technology and Practical Police Work, (1992, Open University Press), p. 71.

2 Assistant Commissioner Peter Winship, Chairman of ACPO's Technical and Research Committee, Computing, 14 April 1994.

3 Operational Policing Review, 1990.

4 ibid., at pp. 80-81.

5 Jane Dudman, Computing, 03 April 1997. 
6 ibid.,

7 ibid.,

8 The RUC is the second largest police force in the UK. For examples of information technology in other police forces see Ackroyd et al., New Technology and Practical Police Work, (Open University Press, 1992) (this book uses the Lancashire Constabulary as an example) and Pounder, Police Computers and the Metropolitan Police: report of an investigation, Greater London Council Police Committee, 1985.

9 Under the Police Act (Northern Ireland) 1970 the Chief Constable of the RUC is responsible for the 'operational control' of policing in Northern Ireland, whereas the Police Authority is charged with maintaining an adequate and efficient police force.

10 Listening to the Community, Working with the RUC, The work of the Police Authority: July 1994-June 1995.

11 A reserve officer is the equivalent to a special officer in Great Britain.

12 An Information Systems Strategy Scoping Study for PANI and the RUC, (The Griew Report) Novem ber 1991.

13 CID investigations include analysis of criminal intelligence, planning operations relating to serious crime, etc. CID may use specialized units such as the drugs or surveillance units. Support services include Central Process Office, Criminal Records Office, fingerprinting, mapping, crime prevention. Special Branch is responsible for the collection, collation, analysis and dissemination of certain types of intelligence, and is involved in covert operations.

14 A review of the position in the rest of the UK also got under way, and culminated in the publication of a National Strategy for Police Information Systems (NSPIS) in 1994.

15 Command \& Control involves issuing information to the men on the ground. It takes the form of incident logging whereby a caller rings in to a police station, this information is logged and resources available are identified. These resources are then deployed and a record is kept of the incident handling.

16 Some similar systems exist in Scotland and England, but the attempt to establish a nationwide system with a common database proved too big for the existing technology to handle and the project had to be abandoned.

17 White Paper, 'Foundations for Policing' (London; HMSO 1996) Cmnd 3249.

18 Service Systems Security Policy, October 1996.

19 Computing, Septem ber 1996.

20 The systems in use in Scotland include databases where all incoming data are hosted in order to let officers know what stage an investigation is at and it also enables analysis of the information in order to identify patterns in crimes, etc. This in turn facilitates a more rapid identification of suspects, and saves time and money regarding police investigations. 